\title{
Protección al consumidor y propuesta Estatal en autorregulación privada y procedimientos administrativos:
} una aproximación inicial $\mathbf{I}^{(* *)(* *)}$

\section{Consumer protection and State proposal in private self-regulation and administrative procedures: an initial approach}

\section{LO QUE SE HA PRETENDIDO RESALTAR EN EL PRESENTE DOCUMENTO SON LAS OPCIONES QUE TIENEEL CONSUMIDOR PARARESOLVER SUS CONTROVERSIAS, DESDE LAAUTORREGULACIÓN, PASANDO POR LAS MODIFICACIONES EFECTUADAS A LOS PROCEDIMIENTOS SEGUIDOS ANTE INDECOPI, PARA CULMINAR CON LA EFECTIVIDAD QUE PUEDEN TENER LAS REDES SOCIALES EN COMPARACIÓN CON LOS MECANISMOS GENERADOS POR EL ESTADO Y LOS PRIVADOS.}

Resumen: ¿Son adecuadas las propuestas Estatales sobre autorregulación privada y procedimientos administrativos en materia de consumo? El presente artículo analiza los retos de su aplicación brindando una reflexión final acerca de los reclamos en redes sociales.

Palabras claves: Franquicia - Autorregulación - Desistimiento - Transacción Extrajudicial - Arbitraje - Consumo - Consumidor - Protección al Consumidor - Indecopi - Redes Sociales - Facebook.

Abstract: Are State proposals on private self-regulation and administrative procedures on consumption adequate? The present papper analyzes the challenges of its application, providing a final reflection on the complaints in social networks.

$\left(^{*}\right.$ Abogado por la Pontificia Universidad Católica del Perú. Magíster en Derecho de la Propiedad Intelectual y de la Competencia por la misma casa de estudios. Docente PUCP en la Maestría de Derecho Propiedad Intelectual y de la Competencia, en la Facultad de Derecho y en el Programa de Segunda Especialidad de Protección al Consumidor. Docente de la Facultad de Derecho de la Universidad Continental. Asesor en temas de Derecho de la Competencia y Propiedad Intelectual. Correo electrónico: mrejanovinschi@pucp.pe

${ }^{* *}$ Dedicado a Sandra, como siempre

$\left.{ }^{* * *}\right)$ Nota del Editor: el artículo fue recibido el 25 de abril del 2017 y su publicación fue aprobada el 20 de junio del mismo año. 


\author{
Protección al consumidor y propuesta Estatal en autorregulación privada y procedimientos \\ administrativos: una aproximación inicial \\ Consumer protection and State proposal in private self-regulation and administrative \\ procedures: an initial approach
}

Keywords: Franchise - Self-Regulation - Withdrawal - Out of Court Settlement - Consumer - Arbitration - Consumer - Consumer Protection - Indecopi - Social Network - Facebook.

\section{Introducción}

En una disputa de consumo tenemos inicialmente dos actores: un consumidor y un proveedor. Dependiendo de cada legislación y política estatal en particular, un consumidor es quien demanda y adquiere un producto y/o un servicio para satisfacer una necesidad de consumo, como destinatario final, retirando el bien o servicio de la cadena de producción. A manera de ejemplo, como característica adicional común en la definición de consumidor en los países miembros de la comunidad Andina, se considera al consumidor como persona natural o jurídica(1). Como contraparte el proveedor será quien brinde el producto o servicio, pudiendo considerarse como tal a un importador, productor, distribuidor o comercializador.

Un consumidor cuenta con diversos derechos reconocidos por cada legislación en particular y la vía internacional. A su vez desea que los recursos que le brinda el ordenamiento jurídico sean efectivos, es decir, será importante, además del derecho sustancial, una herramienta que pueda canalizar sus necesidades de justicia de consumo. Esta preocupación se manifiesta en las Directrices de Naciones Unidas para la Protección del Consumidor:

"los Estados Miembros deben alentar el establecimiento de mecanismos justos, efectivos, transparentes e imparciales para atender las reclamaciones de los consumidores, por medios administrativos, judiciales y alternativos de solución de controversias (...) (deben) establecer o mantener medidas legales o administrativas para permitir que los consumidores (...) obtengan compensación mediante procedimientos oficiales o extraoficiales que sean rápidos, justos, transparentes, poco costosos y accesibles (Naciones Unidas 2016)".

En la Unión Europea también se ha resaltado la importancia entre el derecho sustantivo del consumidor y el instrumento para hacerlo efectivo:

"En un 'Estado de Derecho' la legislación debe establecer por medio de normas Jurídicas generales un equilibrio entre los derechos y las obligaciones de cada cual; en caso de que se lesionen los derechos reconocidos (...) debe existir un procedimiento (judicial o administrativo) para 'hacer Justicia' al particular y, al mismo tiempo, restablecer el equilibrio de intereses deseado por el legislador. Si no existiera tal procedimiento o éste no fuera 'accesible' a los titulares de un interés protegido por el Ordenamiento Jurídico, evidentemente existiría un desfase entre el marco ideado por el legislador y la realidad vivida por los ciudadanos" (Comisión de Comunidades Europeas 1993, 4)(2).

(1) En Colombia, el artículo 5 de la Ley 1480 define al consumidor o usuario como 'toda persona natural o jurídica que, como destinatario final, adquiera, disfrute o utilice un determinado producto, cualquiera que sea su naturaleza para la satisfacción de una necesidad propia, privada, familiar o doméstica y empresarial cuando no esté ligada intrínsecamente a su actividad económica. Se entenderá incluido en el concepto de consumidor el de usuario"; en Ecuador el artículo 2 de la Ley $2000-21$ define al consumidor como "toda persona natural o jurídica que como destinatario final, adquiera, utilice o disfrute bienes o servicios, o bien reciba oferta para ello"; en Bolivia el artículo 5 de la Ley 453 define al consumidor como "las personas naturales o jurídicas que adquieran, utilizan o disfrutan productos o servicios, como destinatarios finales"; en Perú el artículo IV.1 de la Ley 29571 define al consumidor como aquellas "personas naturales o jurídicas que adquieren, utilizan o disfrutan como destinatarios finales productos o servicios materiales e inmateriales, en beneficio propio o de su grupo familiar o social, actuando así en un ámbito ajeno a una actividad empresarial o profesional. No se considera consumidor para efectos de este Código a quien adquiere, utiliza o disfruta de un producto o servicio normalmente destinado para los fines de su actividad como proveedor (...) Los microempresarios que evidencien una situación de asimetría informativa con el proveedor respecto de aquellos productos o servicios que no formen parte del giro propio del negocio (...) En caso de duda sobre el destino final de determinado producto o servicio, se califica como consumidor a quien lo adquiere, usa o disfruta".

(2) Si bien en el marco de la Comunidad Andina existen Decisiones Andinas que regulan la protección al consumidor de manera 
Moisés Rejanovinschi Talledo

Esta justicia puede darse tanto mediante el trato directo entre proveedor y consumidor para resolver sus diferencias, o puede acudir a un tercero imparcial que dirima una controversia concreta. Este tercero puede pertenecer al sector público, como una instancia administrativa o judicial, o al sector privado, y una vez que se inicie alguna vía de resolución de conflictos por el consumidor es posible que concluya mediante una forma autocompositiva.

Otra modalidad, de resolver una controversia, que no se encuentra mediante un conocimiento directo del consumidor, pero que puede percibirse indirectamente, mediante el prestigio que puede transmitir una franquicia. Un fenómeno reciente, y que es necesario mencionar, es la exposición de los reclamos de los consumidores en redes sociales pertenecientes a proveedores.

En el presente documento, a raíz de diversas propuestas emitidas por el Instituto Nacional de Defensa de la Competencia y de la Protección de la Propiedad Intelectual - Indecopi (En adelante "Indecopi") que inciden en el Código de Protección y Defensa del Consumidor (En adelante, "Código de Consumo") comentaremos aspectos sobre la autorregulación y la franquicia, las formas autocompositivas de concluir una controversia en sede administrativa en Indecopi, y el fenómeno de redes sociales como medio utilizado por los consumidores para interponer reclamos.

\section{Autorregulación y Franquicias}

Una iniciativa del proveedor para satisfacer alguna discrepancia sobre los productos y servicios que se brindan a los consumidores consiste en la autorregulación, pudiendo definirse como "la estrategia alternativa para salvar los déficits de una regulación pública tradicional incapaz de proteger por sí sola intereses públicos y conseguir la satisfacción de éstos de forma indirecta" (García 2011, 559).
La autorregulación también se entiende como un grupo de empresas o un sector empresarial que acuerdan actuar según una serie de reglas o principios, siendo su participación voluntaria. Las ventajas frente a la regulación tradicional incluyen: mayor nivel de exigencia frente a la normativa estatal y mayor nivel de cumplimiento, flexibilidad, completa de manera más célere vacíos legales, mayor experiencia técnica, disminución de costos, incremento de valores y ética empresarial, mayor competencia, conservación de recursos y costos gubernamentales. Asimismo la autorregulación plantea los siguientes retos: fuerza insuficiente de los instrumentos autorregulatorios, dificultad en supervisión y cumplimiento, riesgo de captura, free-riders $u$ oportunismo de proveedores que no participan en la autorregulación, insuficiente cobertura del mercado, favoritismo de empresas dominantes, distorsión en la competencia pues la autorregulación podría crear barreras de entrada, obligatoriedad en la rendición de cuentas, incremento de costos directos en las empresas que implementan la autorregulación (OECD 2015, 11, 18-21).

Se considera la autorregulación como una estrategia alternativa del proveedor frente a los mecanismos que brinda el Estado para resolver las controversias de consumo. En el caso peruano el Estado ha dispuesto que sea Indecopi quien cuente con competencia primaria para resolver estas contiendas ${ }^{(3)}$. El éxito de la autorregulación dependerá si es más eficiente, pudiendo medirse comparativamente con los mecanismos tradicionales que brinda el Estado

indirecta y sectorial (a manera de ejemplo la Decisión 486, Decisión 608, Decisión 638, Decisión 619), actualmente no existe una Decisión Andina que regula expresamente la protección general de los consumidores. Sin embargo, esto no ha sido obstáculo para que el Estado Peruano implemente mecanismos en la defensa de los derechos de los consumidores.

(3) Según el artículo 105 del Código de Consumidor. En materia de reparaciones a los consumidores, Indecopi otorga medidas correctivas a los consumidores, equivalentes a indemnizaciones a cuenta o daños emergentes. Véase Moisés Rejanovinschi Talledo, "Los dilemas para consumidor justicia: algunos alcances de la tutela procesal del consumidor en la vía administrativa y el arbitraje de consumo," Revista Derecho PUCP 75 (2015): 235. 


\section{Protección al consumidor y propuesta Estatal en autorregulación privada y procedimientos administrativos: una aproximación inicial Consumer protection and State proposal in private self-regulation and administrative procedures: an initial approach}

a los consumidores, considerando factores como la celeridad en resolver la controversia, si la compensación es plena o parcial, si es vinculante, entre otras características a comparar.

Se pueden clasificar los instrumentos autorregulatorios en normativos, declarativos y resolutivos. Los instrumentos normativos definen los medios que permiten cumplir los fines de una actividad profesional, pudiendo encontrarse entre ellos a los códigos éticos o de conducta, las normas técnicas, manuales de buenas prácticas y protocolos. Los instrumentos declarativos certifican el cumplimiento de reglas técnicas y éticas, y pueden incluir autocertificaciones o certificaciones emitidas por terceros, marcas de certificación. Los instrumentos resolutivos tienen como finalidad el control de la ejecución de las reglas, como sanciones disciplinarias y resoluciones arbitrales (Darnaculleta 2002, 494-509). En materia de protección al consumidor, y como herramienta de resolución de controversias será importante que la autorregulación sea de obligatorio cumplimiento para el proveedor, pues la ejecutoriedad será trascendente para que un consumidor decida adoptar esta vía.

Para una autorregulación eficiente será importante la interiorización en el proveedor de reglas superiores al marco legal, y que estas reglas, sea que las maneje o ejecute un proveedor o un organismo que agrupe a proveedores - por ejemplo de carácter gremial - sean de efectivo cumplimiento. Caso contrario, nos encontraríamos ante la aplicación del marco legal vigente.

Un ejemplo de autorregulación gremial en los Estados Unidos de Norteamérica es la Better Business Bureau - BBB, entidad sin fines de lucro, encargada de brindar información sobre la reputación de una empresa, colaborar en controversias entre proveedores y consumidores mediante la mediación, vigilar si la publicidad se encuentra conforme a la legislación, y también vigilar a organizaciones sin fines de lucro para verificar el uso de las donaciones que reciben, e informar sobre posibles estafas y ofertas discutibles ${ }^{(4)}$.

En el ámbito peruano contamos con la Defensoría del Asegurado, entidad que según su reglamento, ha sido creada por la Asociación Peruana de Empresas de Seguros cuya finalidad es la protección, mediante solución de controversias, de los derechos de los asegurados o usuarios de seguros de servicios de seguro privado en materia de rechazos o liquidación de coberturas de siniestros ${ }^{(5)}$. Otorga indemnizaciones hasta de US \$ $50,000.00$, y en el 2015 se resolvieron ciento cincuenta y seis reclamaciones, de las cuales treinta y cuatro fueron fundadas, ciento ocho infundadas y catorce improcedentes. A su vez, de las setenta y uno Resoluciones revisadas en el mismo año en segunda instancia, sesenta y tres ratificaron lo resuelto en primera instancia mientras que 8 fueron revocadas ${ }^{(6)}$.

Asimismo, la Defensoría del Cliente Financiero tienen como finalidad resolver y prevenir controversias entre usuarios y prestadores de servicios financieros ${ }^{(7)}$, encontrándose afiliadas diecinueve entidades ${ }^{(8)}$. De acuerdo a los literales f) y g) del artículo 9 de su Reglamento( ${ }^{(9)}$, la Defensoría no es competente para resolver reclamos cuyo petitorio exceda

(4) Véase Better Bussines Bureau, “¿Qué es el BBB?,” https://www.bbb.org/indy/get-to-know-us/about-us/que-es-el-bbb/ (consultada el 21 de febrero de 2017).

(5) Véase Defensoría del Asegurado, "Reglamento de la Defensoría del Asegurado," http://www.defaseg.com.pe/reglamento. html (consultada el 23 de febrero de 2017).

(6) De acuerdo a su Informe Final del 2015. Véase Defensoría del Asegurado, "Año 2015 Informe Final 2015," http://www. defaseg.com.pe/resoluciones.html (consultado el 23 de febrero de 2017).

(7) Véase Defensoría del Cliente Financiero, “¿Quienes somos?,” http://www.dcf.com.pe/quienes_somos/index.asp (consultada el 03 de marzo de 2017).

(8) Véase Defensoría del Cliente Financiero, "Directorio de Entidades Afiliadas," http://www.dcf.com.pe/entidades_afiliadas/ directorio_entidades.asp (consultada el 03 de marzo de17).

(9) Véase Defensoría del Cliente Financiero, "Publicaciones del DFC. Reglamento," http://www.dcf.com.pe/publicaciones/index. asp (consultada el 03 de marzo de 2017). 
Moisés Rejanovinschi Talledo

de S/ 70,000.00 o el otorgamiento de indemnizaciones o resarcimiento por las entidades financieras a favor de sus clientes, ni aplicar sanciones contra las entidades financieras. En el año 2015 ingresaron 486 reclamos, de los cuales el 42\% se resolvió a favor del cliente ${ }^{(10)}$.

Un ejemplo adicional sobre autorregulación la tenemos en la Defensoría del Cliente Automotor, entidad que según el artículo 1 de su Reglamento(11), tiene como finalidad atender reclamos formulen consumidores automotores y solucionar conflictos ente consumidores y asociados de la Asociación Automotriz del Perú (en adelante, "AAP"). Conforme a su artículo 4 aplica las disposiciones del Código de Protección y Defensa del Consumidor referidas a medidas correctivas ${ }^{(12)}$. No se ha encontrado en la web de la Defensoría estadísticas sobre reclamos del año 2015, sin embargo en su boletín Informativo DCA-01-2016 afirman que en el 2016 el 69\% de los casos ingresados concluyeron por conciliación entre las partes ${ }^{(13)}$.

También se ha creado el Defensor del Cliente Inmobiliario, creado por la Asociación de Desarrolladores Inmobiliarios, cuya finalidad es "dar respuesta a todos los reclamos y requerimientos que tenga el cliente, garantizando el acceso al reclamo de forma que el cliente inmobiliario obtenga una resolución independiente de las partes en conflicto, por medio de conciliaciones o arbitrajes autónomos"(14). La Asociación cuenta con 25 miembros ${ }^{(15)}$.

En materia de protección al Consumidor, el Servicio de Atención al Ciudadano - SAC, recibió en el 2015 19,991 reclamos de servicios financieros, 2,535 en servicios de seguros, 1,533 en automóviles, accesorios, repuestos y mecánica, 661 en inmuebles, corretaje, alquileres y vivienda (INDECOPI 2015, 26).

En cuanto al esquema de resolución de conflictos en el Indecopi, se cuentan con los procedimientos ordinarios y los sumarísimos, diferenciándose ambos en cuantía y materia: los sumarísimos son competentes para conocer denuncias cuya cuantía no supere 3 UIT, y en materia sobre falta de atención a reclamos y requerimientos de información, métodos abusivos de cobranza, falta de entrega del producto, así como denuncias por incumplimiento de medidas correctivas, incumplimiento de acuerdos conciliatorios e incumplimiento y liquidación de costas y costos; los ordinarios son competentes en cuantías mayores a 3 UIT o inapreciables en dinero, así como reclamos por productos o sustancias peligrosas, actos de discriminación o trato diferenciado, servicios médicos, actos que afecten intereses colectivos o difusos ${ }^{(16)}$.

En el sumarísimo el Jefe del Órgano Resolutivo de Procedimiento Sumarísimo es la primera instancia administrativa y la Comisión de Protección al Consumidor

(10) Véase Defensoría del Cliente Financiero, "Publicaciones del DFC. Estadísticas," http://www.dcf.com.pe/publicaciones/ Estadisticas-31-12-2015.pdf (consultada el 05 de marzo de 2017).

(11) Véase Defensoría del Consumidor Automotor, "Reglamento de la Defensoría del Consumidor Automotor," http://www.dca. org.pe/pdf/reglamento_de_la_defensoria_del_consumidor_automotor.pdf (consultada el 05 de marzo de 2017).

(12) De acuerdo a artículos periodísticos, se puede apreciar que la Defensoría del Cliente Automotor viene ejerciendo aproximadamente sus funciones desde marzo del 2015. En estos enlaces pueden encontrar un par de ejemplos: véase Perú 21, "¿Problemas con la compra de tu vehículo? Entonces esto puede interesarte," http://peru21.pe/mis-finanzas/problemascompra-tu-vehiculo-entonces-esto-puede-interesarte-2214553 (consultada el 20 de marzo de 2017) y El Comercio, "Crearon Defensoría del Cliente Automotor para atender reclamos," http://elcomercio.pe/economia/peru/crearon-defensoria-clienteautomotor-atender-reclamos-noticia-1796820 (consultada el 20 de marzo de 2017).

(13) Véase página 1 del Informativo DCA-01-2016, disponible en: Defensoría del Consumidor Automotor, "Informativos Informativo DCA-01-2016," http://www.dca.org.pe/informativos/ (consultado el 05 de marzo de 2017).

(14) Véase Asociación de Desarrolladores Inmobiliarios, "Defensor del Cliente Inmobiliario," http://www.adiperu.pe/defensor-delcliente-inmobiliario/ (consultada el 15 de marzo de 2017).

(15) Véase Asociación de Desarrolladores Inmobiliarios, "Miembros de ADI," http://www.adiperu.pe/miembros-adi/ (consultada el 15 de marzo de 2017). Asimismo, de la revisión del portal virtual, no se han conseguido estadísticas en materia de reclamos.

(16) Conforme al artículo 125 del Código de Consumo. 


\author{
Protección al consumidor y propuesta Estatal en autorregulación privada y procedimientos \\ administrativos: una aproximación inicial \\ Consumer protection and State proposal in private self-regulation and administrative \\ procedures: an initial approach
}

competente resuelve en apelación; en el ordinario la Comisión de Protección al Consumidor competente resuelve en primera instancia administrativa y la Sala de Protección al Consumidor resuelve en apelación. Sobre determinados aspectos en los cambios normativos en el procedimiento nos pronunciaremos en líneas posteriores.

En el caso de denuncias ingresadas a los Órganos Resolutivos de Procedimientos Sumarísimos, en el 2015 ingresaron 5,736 denuncias en materia de servicios financieros, 605 denuncias en materia de seguros, 377 denuncias por venta, reparación y mantenimiento de vehículos, y 301 denuncias por construcción e inmobiliario (INDECOPI 2015, 62). Este Órgano Resolutivo en el 2015 concluyó en resolver 5,479 denuncias en el sector financiero, 520 denuncias en el sector de seguros, 362 denuncias en venta, mantenimiento y reparación de vehículos, y 287 denuncias en materia de construcción e inmobiliario (INDECOPI 2015, 71).

En el caso de las denuncias resueltas el 2015 por el Órgano Sumarísimo, en el sector financiero 1789 fueron declaradas fundadas o fundadas en parte, en el sector seguros 132 fueron declaradas fundadas totalmente o en parte, 98 denuncias se han declarado fundada en todo o en parte en venta, mantenimiento y reparación de vehículos, 70 denuncias se han declarado fundadas, en todo o parte, en construcción e inmobiliario (INDECOPI 2015, 72).

En el caso de las Comisiones de Protección al Consumidor, en el 2015 ingresaron 2,065 denuncias sobre servicios financieros, 743 denuncias en el sector construcción e inmobiliario, 539 denuncias en venta, mantenimiento y reparación de vehículos, y 496 denuncias en materia de seguros (INDECOPI 2015, 135). Como también cuenta con funciones de resolución de controversias en segunda instancia, en el 2015 ingresaron 1,773 apelaciones en el sector financiero, 128 apelaciones en seguros, 104 apelaciones en sector construcción e inmobiliario, y 85 apelaciones en materia de venta, mantenimiento y reparación de vehículos (INDECOPI 2015, 136).

En el mismo año las Comisiones de Protección al Consumidor concluyeron 1,728 expedientes de servicios financieros, 783 expedientes en el sector construcción e inmobiliario, 557 denuncias en materia de venta, mantenimiento y reparación de vehículos, y 426 denuncias en materia de seguros
(INDECOPI 2015, 140). De las denuncias concluidas en el sector financiero 479 se declararon fundadas (INDECOPI 2015, 141), en el sector inmobiliario 386 se declararon fundadas (INDECOPI 2015, 142), en materia de vehículos 177 se declararon fundadas y en el sector seguros 103 se declararon fundadas (INDECOPI 2015, 143).

En lo referente a lo resuelto como segunda instancia, se resolvieron 1,683 apelaciones correspondientes al sector financiero, 109 apelaciones se resolvieron en el sector construcción e inmobiliario, 104 apelaciones se resolvieron en materia de seguros, 78 apelaciones se resolvieron en venta, mantenimiento y reparación de vehículos (INDECOPI 2015, 144). De las apelaciones resueltas en materia del sector financiero 1,149 confirma lo resuelto por la primera instancia administrativa (INDECOPI 2015, 145).

En la Sala Especializada de Protección al Consumidor, en el 2015 ingresaron 2,490 apelaciones (INDECOPI 2015, 218) y se resolvieron 2,220 (INDECOPI 2015, 219). En el ámbito del sector financiero la Sala resolvió 506 expedientes, en el sector construcción e inmobiliario 217 expedientes, en materia de seguros 154 expedientes, en venta, mantenimiento y reparación de vehículos 132 expedientes (INDECOPI 2015, 220). En lo referente al recurso de revisión - facultad con la que actualmente no cuenta pues se ha derogado dicho recurso - ingresaron 1,218 recursos (INDECOPI 2015, 221), y se resolvieron en el mismo año 1,168 expedientes (INDECOPI 2015, 222). De los recursos de revisión 835 se declararon improcedentes, 181 se declararon infundados, 150 fundados, 1 resolución se declaró nula y 1 se determinó sustracción de materia (INDECOPI 2015, 223).

De acuerdo a las cifras mencionadas en el caso peruano se evidencia que los consumidores prefieren acudir al Indecopi a 
Moisés Rejanovinschi Talledo

resolver sus controversias, y dado que la autorregulación se encuentra, aunque de manera tímida, en algunos sectores económicos, Indecopi ha aprobado, mediante la Resolución de la Presidencia del Consejo Directivo del Indecopi No. 216-2016-INDECOPI/COD(17), las "Recomendaciones generales para la creación de Defensorías del Consumidor" (En adelante, "Recomendaciones de Defensorías del Consumidor"). El sustento de las Recomendaciones de Defensorías del Consumidor, según su parte considerativa, se encuentra en el inciso 6 del artículo VI del Código de Consumo, relevante para el presente documento:

"El Estado garantiza mecanismos eficaces y expeditivos para la solución de conflictos entre proveedores y consumidores. Para tal efecto, promueve que los proveedores atiendan y solucionen directa y rápidamente los reclamos de los consumidores, el uso de mecanismos alternativos de solución como la mediación, la conciliación y el arbitraje de consumo voluntario, y sistemas de autorregulación; asimismo, garantiza el acceso a procedimientos administrativos y judiciales ágiles, expeditos y eficaces para la resolución de conflictos y la reparación de daños".

A su vez, la autorregulación también está considerada en el Eje de Política 3 de la Política Nacional de Protección y Defensa del Consumidor(18) (En adelante, "Política de Protección al Consumidor") cuyo objetivo en el Eje citado es "promover el establecimiento de mecanismos expeditivos de prevención y solución de conflictos a nivel nacional, impulsando su simplificación", señalando expresamente que "es parte de la Política Nacional el impulso de mecanismo de solución en el ámbito privado puesto que son los proveedores, que forman parte del Sistema, los llamados a incentivas la solución de conflictos a través de la creación de mecanismos de solución de controversias". Si bien son recomendaciones, existen aspectos a tener en cuenta. El literal g) del artículo $\mathrm{V}$, referido a los reclamos, afirma que:

"Si bien la tramitación de un reclamo ante una Defensoría no impide que el consumidor reclamante acuda a la autoridad competente para solicitar la protección de sus derechos, para efectos de iniciar un reclamo ante la Defensoría, el consumidor no podrá iniciar de manera paralela, mantener en trámite o haber concluido un reclamo o procedimiento ante otra autoridad administrativa, judicial o arbitral por los mismos hechos que son objeto de reclamo tramitado ante una Defensoría".

Cabe preguntarse si este extremo de evitar la vía paralela en los reclamos se interpretaría como un impedimento o limitación del consumidor del acceso a la justicia. En principio la autorregulación mediante una defensoría del consumidor no impide que el consumidor después de acudir a ella o simultáneamente acuda a la vía ordinaria, por lo que no puede entenderse como requisito previo. La recomendación apunta a la exclusión cuando coinciden temporalmente al estar "abiertas" dos vías a la vez (la autorregulada defensoría del consumidor vs el procedimiento administrativo, judicial o arbitral).

Desde la perspectiva de la teoría procesal, si nos encontramos ante la misma pretensión, estaremos ante una falta de interés para obrar, conocido como la "necesidad de acudir al órgano jurisdiccional, como único medio capaz de procesal y posteriormente declarar una decisión respecto del conflicto" (Monroy 1994, 124). También el interés para obrar se entiende como un juicio de utilidad, es decir, "existe el interés en la declaración de certeza de tutela (...) cuando dicha declaración de certeza (...) produzcan una utilidad actual para su titular" (Rocco, 1982, 343). Esta necesidad o utilidad se puede trasladar a la vía arbitral o judicial. Sin embargo, si la autorregulación, en la recomendación de Defensoría del Consumidor propuesta por Indecopi, consideramos que

(17) Publicada en el Diario Oficial "El Peruano" el 17 de diciembre de 2016.

(18) Aprobada por Decreto Supremo No. 006-2017-PCM, publicada en el Diario Oficial "El Peruano" el 27 de enero de 2017. 


\section{Protección al consumidor y propuesta Estatal en autorregulación privada y procedimientos administrativos: una aproximación inicial Consumer protection and State proposal in private self-regulation and administrative procedures: an initial approach}

el consumidor pueda en paralelo acudir a la autorregulación propuesta por el proveedor o un grupo de ellos, pues lo ideal será que compita en efectividad en comparación con lo que pueda brindar la vía ordinaria que pueda escoger el consumidor.

Adicionalmente, si en un procedimiento administrativo existe la posibilidad de culminar la controversia mediante una conciliación, por qué no asimilar la autorregulación de la Defensoría del Consumidor como una manera de encontrar una solución a la controversia. Recordemos que el literal i) del artículo V de las "Recomendaciones de Defensorías del Consumidor" se indica que el incumplimiento de un acuerdo conciliatorio suscrito ante un Defensor Gremial puede ser sancionado ante Indecopi ${ }^{(19)}$.

A mayor abundamiento, el literal $k$ ) del artículo $\mathrm{V}$ de la "Recomendaciones de Defensorías del Consumidor" señala que la Resolución que emita el Defensor o Tribunal Gremial "no vinculará per se al consumidor reclamante, quien deberá comunicar a la Defensoría su voluntad de aceptar lo resuelto en ella. Su silencio deberá interpretarse como rechazo a lo resuelto. Los proveedores afiliados (...) se encontrarán obligados a aceptar lo resuelto en el recamo una vez aceptado por el consumidor". En otras palabras, si la solución que emita el Defensor Gremial será vinculante si acepta el consumidor, y a su vez, si se llega a una conciliación mediante el Defensor Gremial, y si el proveedor no la cumple será sancionado ${ }^{(20)}$, no se comprende la exclusión de la vía paralela. En este extremo sugerimos que se excluya la posibilidad de impedir la vía paralela en caso de acudir al Defensor del Consumidor.

Lo que también indican las "Recomendaciones de Defensorías del Consumidor" es el plazo para resolver la controversia no debe durar, preferentemente, más de 30 días calendarios desde la recepción del reclamo(21). Como mecanismo compite comparativamente con el procedimiento sumarísimo, regulado en los artículos 124 y siguientes del Código de Consumo. En el caso de los procedimientos sumarísimos cada instancia tiene una duración de 30 días hábiles ${ }^{(22)}$. Sin embargo, en el sumarísimo la regla general es la prueba documentaria ${ }^{(23)}$.

En materia de protección al consumidor sería interesante que la autorregulación incluyera una indemnización plena y no solamente una medida correctiva reparadora, si es que se afirma que una ventaja de la autorregulación consiste en establecer obligaciones superiores a las legales.

En las vías ordinarias o tradicionales en materia de protección al consumidor, el procedimiento administrativo seguido ante Indecopi otorga

(19) “Artículo V

(...) i) incumplimiento de acuerdo conciliatorio: el incumplimiento de un acuerdo conciliatorio suscrito ante un Defensor Gremial del Consumidor puede dar inicio a un procedimiento sancionador ante el Instituto Nacional de Defensa de la Competencia y de la Protección de la Propiedad Intelectual, según lo dispuesto en el literal a) del artículo 106 y el artículo 108 de la Ley No. 19571, Código de Protección y Defensa del Consumidor".

Debe entenderse Ley 29571 al ser un error material.

(20) Además de solicitar un procedimiento sancionador por incumplimiento de acuerdo conciliatorio ante Indecopi, las "Recomendaciones de Defensorías del Consumidor" sugieren en el literal I) del artículo V que las defensorías habiliten un procedimiento de incumplimiento incluyendo como sanción la amonestación pública a través de medios de comunicación. Lo que deberá evaluarse es la efectividad de la sanción.

(21) Según el artículo V literal j) de las "Recomendaciones de Defensorías del Consumidor".

(22) Este plazo es mayor conforme a la Directivas 007-2013/DIR-COD-INDECOPI y Directiva 003-2014/DIR-COD-INDECOPI, que modifican reglas complementarias al procedimiento sumarísimo. Asimismo, el Decreto Legislativo 1308 modifica el procedimiento sumarísimo a solo 2 instancias.

(23) Artículo 26 del Código de Consumo:

"Artículo 126 (...) Se ofrecen únicamente medios probatorios documentales con la presentación de la denuncia, el escrito de descargos, el recurso de apelación o en su absolución, según corresponda, sin perjuicio de la facultad de la autoridad para requerir, de oficio, la actuación de algún medio probatorio de naturaleza distinta". 
Moisés Rejanovinschi Talledo

medidas correctivas reparadoras y complementarias: las medidas correctivas complementarias, según el artículo 116 del Código de Consumo, tienen por objeto revertir los efectos de la conducta infractora y evitar que se produzcan en el futuro; las medidas correctivas reparadoras, según el artículo 115 del Código de Consumo, resarcen las consecuencias patrimoniales directas e inmediatas ocasionadas al consumidor. En otra oportunidad señalamos que las medidas correctivas reparadoras son "indemnizaciones a cuenta" y que la opción del legislador de restringir el otorgamiento de una indemnización plena en sede administrativa no ha sido la correcta (Rejanovinschi 2015, 235 y siguientes).

Los proveedores que se sometan voluntariamente a esta defensoría gremial no deberían contar con algún recelo, ya que el consumidor debe acreditar previamente, para que sea indemnizado, si hubo afectación en alguno de sus derechos (Osterling 1985, 398)(24) y si esa afectación es la causa de la reparación del daño que reclama. Si se diera esta característica dentro de la autorregulación competiría con el arbitraje de consumo ${ }^{(25)}$.

Posiblemente la posibilidad de otorgar una indemnización a los consumidores, y el carácter unilateral del arbitraje de consumo ha contribuido para que se implemente de manera muy gradual(26), contando a la fecha con 29 proveedores adheridos en la Junta Arbitral Piloto de la Sede Central de Indecopi(27).

Una manera adicional por la cual el proveedor puede autoimponerse reglas adicionales a las de la legislación la encontramos en las franquicias. Este contrato es de carácter mercantil e implica "combinar la reputación, la innovación (activo intangible), los conocimientos técnicos y la experiencia del innovador (el franquiciante) con la energía, el interés y la inversión de otra parte (el franquiciatario) para llevar a cabo transacciones de suministro y venta de productos y servicios"1(28). En este contrato, las partes son el franquiciante (quien cuenta con la franquicia) y el franquiciado (a quien se le otorga la franquicia).

Este contrato de franquicia cuenta con una serie de ventajas para el franquiciado: se cuenta con una preventa de clientes, ya que se franquician productos y una metodología que cuenta con relativo éxito en la concurrencia en un mercado, y brinda a los consumidores cierto nivel de calidad $^{(29)}$.

(24) Osterling señala que para la procedencia de una indemnización es necesario la concurrencia de tres elementos: la inejecución de la obligación, la imputabilidad del deudor y el daño.

(25) Si bien el Poder Judicial otorga indemnizaciones plenas, el arbitraje tiene como ventaja la celeridad, flexibilidad en el procedimiento e instancia única.

(26) Otras razones de esta implementación gradual la atribuimos a la gratuidad, la unidireccionalidad y que las Juntas Arbitrales se implementen en gobiernos regionales y locales. Consultar: Moisés Rejanovinschi Talledo, "Los dilemas para consumidor justicia: algunos alcances de la tutela procesal del consumidor en la vía administrativa y el arbitraje de consumo," Revista Derecho PUCP (2015): 235 y siguientes.

(27) Véase Instituto Nacional de Defensa de la Competencia y de la Protección de la Propiedad Intelectual, Arbitraje de Consumo, Junta Arbitral de Consumo Piloto "Registro de Proveedores adheridos al sistema de Arbitraje de Consumo," https://www. indecopi.gob.pe/documents/51084/402080/RPA-SISAC 2017/f17e8af4-7d14-a0ff-759a-e27c266f59de (consultada el 20 de febrero de 2017). Como una de las características del arbitraje de consumo es la voluntariedad, para acceder a resolver una controversia en esta modalidad se puede contar con una cláusula de convenio arbitral, con la adhesión previa del proveedor al Sistema de Arbitraje de Consumo, o en el caso de no contar con ninguna de las anteriores mediante la aceptación expresa del proveedor luego que el consumidor solicite resolver la controversia mediante este tipo de arbitraje. La descripción de las modalidades indicadas se encuentran en los artículos 17 y 18 del Decreto Supremo 046-2011-PCM.

(28) Véase lan Cockburn, "Franquicias y licencias: ¿qué son y en qué medida pueden beneficiarnos?," http://www.wipo.int/sme/ es/documents/franchising.htm (consultada el 01 de marzo de 2017).

(29) Véase International Franchise Association, About Franchising, "What are the advantages and disadvantages of owning a franchise?," http://franchise.org/what-are-the-advantages-and-disadvantages-of-owning-a-franchise (consultada el 01 de marzo de 2017). Traducción Libre. El texto original es el siguiente: 


\section{Protección al consumidor y propuesta Estatal en autorregulación privada y procedimientos administrativos: una aproximación inicial Consumer protection and State proposal in private self-regulation and administrative procedures: an initial approach}

Las obligaciones del franquiciante consisten en trasferir el know how, licenciar los signos distintivos, brindar asistencia técnica, otorgar exclusividad, no obstaculizar el proceso de franquicia, suministrar productos o insumos o servicios que se han pactado. En cuanto al franquiciado tiene como obligaciones cumplir con los pagos pactados (como pago de entrada y pagos periódicos, pago por uso de signos distintivos), ubicar el establecimiento en el lugar autorizado, no competir con el franquiciante, confidencialidad y remitir información sobre la gestión de la franquicia (Soria y Osterling 201, 94-104).

Parte del contrato de franquicia lo conforma la licencia de marca. La marca o signo distintivo, dependiendo del posicionamiento de un proveedor en el mercado, genera prestigio y transmite confianza. El rol de los signos distintivos es importante en el contrato franquiciante, pues se transmite información valiosa para los consumidores. Así, los signos, cumplen, entre otras funciones, la función distintiva y la función indicadora de la calidad.

En la función distintiva se vincula un signo que diferencia un producto y/o un servicio con un origen empresarial: "al contemplar una marca puesta en relación con un producto o un servicio, el consumidor piensa lógicamente que el producto o servicio procede de una determinada empresa: de aquella empresa que proceden todos los productos o servicios de la misma clase que están dotados de la misma marca" (Fernández 1978, 35).

En la función indicador de la calidad el consumidor atribuye a la marca una calidad determinada, en función del ensayo error al satisfacer necesidades de consumo:

"En relación con el artículo de marca que es conocido por propia experiencia o bien por consecuencia de las informaciones proporcionadas por otros consumidores (...) el consumidor piensa que el artículo posee aquellas características que le son propias de todos los artículos del mismo género que llevan sobre sí la misma marca (Fernández 1978, 35, 40)"(30).

La calidad del signo distintivo genera confianza, y ésta contribuye a superar el déficit informativo, ya que "un nombre con trayectoria ayuda a resolver el problema de la desinformación del consumidor acerca de la calidad de su servicio; el consumidor puede presumir el nombre o marca como una señal de calidad" (Weingarten 2011, 81).

Como se puede observar, una franquicia disminuye costos de transacción en varios puntos de la cadena de producción. En cuanto a la oferta de un producto o un servicio, para una persona que concurre en un mercado determinado y pueda afianzarse en el mismo, debe contar con algún tipo de plan operativo que evalúe si lo que oferta puede gozar de la preferencia de los consumidores. Caso contrario, puede ser expulsado del mercado. Esa información no la conoce de antemano el ofertante. Lo que una franquicia permite a un futuro ofertante, ante un riesgo de ser exitoso en un mercado determinado, es conocer un modelo acreditado que funciona en el mercado y disminuir dicho peligro. En cuanto a la demanda, el consumidor ya conoce la calidad de un producto o un servicio que funciona como franquicia, disminuyéndose el ensayo error en que podría incurrir el destinatario final del producto o servicio.

En el artículo 67 del Decreto Legislativo 1075 se indica que "el licenciante responde ante los consumidores por la calidad e idoneidad de los productos o servicios licenciados como

"This gives the franchisee the benefits of a pre-sold customer base which would ordinarily takes years to establish. A franchise increases your chances of business success because you are associating with proven products and methods. Franchises may offer consumers the attraction of a certain level of quality and consistency because it is mandated by the franchise agreement".

(30) También determinadas marcas, como las notorias o renombradas, por la implantación en la mente de los consumidores, tienen una función adicional, la del goodwill, prestigio o buena fama de la marca. 
Moisés Rejanovinschi Talledo

si fuese el productor o prestador de éstos". Entiéndase la idoneidad como la expectativa que se genera en el consumidor, la misma que se contrasta con lo que efectivamente recibe ${ }^{(31)}$. No ha sido ajeno a nuestro medio algunas controversias vinculadas a la protección al consumidor y a otros ámbitos en los que han estado involucradas franquicias ${ }^{(32)(33)}$. Varias de estas controversias incluso se viralizan por medios virtuales, como ejemplo en redes sociales.

Si el titular de la franquicia se verá afectado por los actos que efectúe el licenciatario de la marca, deberá "curarse en salud" y redactar cláusulas en el contrato franquiciante que lo protejan. Su prestigio está expuesto en el mercado y tendrá que cuidarlo, por lo que deberá establecer una serie de obligaciones para velar porque ese intangible se mantenga intacto. Este contrato deberá incluir pautas de supervisión, penalización e incluso resolución del contrato ya que la marca de una franquicia transmite información acerca de la calidad de un producto o un servicio.

Una manera en que indirectamente se puede favorecer a los consumidores se da mediante obligaciones que establezca el franquiciante en el contrato por la cual el franquiciado remita el número de reclamos de forma mensual, tanto los consignados en el libro de reclamaciones como en redes sociales. Esta obligación ayudará a que se analice si el franquiciado está brindando un buen servicio. Adicionalmente se puede exigir mediante el contrato de franquicia que el franquiciado resuelva los reclamos en un plazo inferior a treinta días calendario quizá veinte o menos-, siendo más competitiva esta obligación en comparación con lo señalado actualmente en el Código de Consumo(34).
A su vez puede exigir el franquiciante contractualmente que el franquiciado cuente con una cantidad mínima de personal en cada local, características tecnológicas mínimas, cumplimiento de derechos laborales del personal, comunicación fluida con el franquiciante y con los consumidores incluyendo redes sociales y otras plataformas, contar con certificación de calidad, que el local donde se situará la franquicia se encuentre en una avenida principal o cercana a ella, chats y buzones de sugerencias para brindarle una mejor experiencia al consumidor. Una franquicia, pues, incrementa la confianza entre el proveedor y el consumidor.

\section{Modificaciones en los procedimientos seguidos ante Indecopi}

El Congreso de la República delega al Poder Ejecutivo, mediante la Ley 30506, facultades de legislar en materia de reactivación económica y formalización, entre otros supuestos, autorizando además a modificar procedimientos administrativos con la finalidad que sean optimizados y facilitar el desarrollo de actividades económicas.

El consumidor, como destinatario final de las transacciones de un mercado, es quien decide mediante votos en dinero qué ofertantes

(31) Artículo 18 del Código de Consumo:

"Artículo 18. Idoneidad. Se entiende por idoneidad la correspondencia entre lo que un consumidor espera y lo que efectivamente recibe, en función de lo que se le hubiera ofrecido, la publicidad e información transmitida, las condiciones y circunstancias de la transacción, las características y naturaleza del producto o servicio, el precio, entre otros factores, atendiendo a las circunstancias del caso. La idoneidad es evaluada en función a la propia naturaleza del producto o servicio y a su aptitud para satisfacer la finalidad para la cual ha sido puesto en el mercado (...)".

(32) Véase Capital, "Domino's Pizza anuncia el cierre de todos sus establecimientos en Perú," http://www.capital.com.pe/dominospizza-noticia 765713.html (consultada el 03 de setiembre de 2015)

(33) Véase Capital, "Cerraron McDonald's de San Isidro tras hallar cucarachas e insectos," http://www.capital.com.pe/2015-1002-cerraron-mcdonald-039-s-de-san-isidro-tras-hallar-cucarachas-e-insectos-noticia 841018.html (consultada 02 de octubre de 2015)

(34) Artículo 24 del Código de Consumo: "Artículo 24.1. (...) los proveedores estarán obligados a atender los reclamos presentados por sus consumidores y dar respuesta a los mismos en un plazo no mayor a treinta (30) días calendario. Dicho plazo puede ser extendido por otro igual cuando la naturaleza del reclamo lo justifique (...)". 


\section{Protección al consumidor y propuesta Estatal en autorregulación privada y procedimientos administrativos: una aproximación inicial Consumer protection and State proposal in private self-regulation and administrative procedures: an initial approach}

prevalecerán en el mercado. Un actor tan importante merece el reconocimiento de derechos y herramientas que ayuden a que efectivamente se cristalicen los mismos.

Dentro del contexto de delegación de facultades, mediante el Decreto Legislativo $1308^{(35)}$ se modifican diversos artículos del Código de Consumo. Comentaremos en esta parte del documento las facultades que se pueden delegar a entidades privadas, las formas autocompositivas de conclusión del procedimiento administrativo, si es posible el rechazo in límine de una denuncia, y la eliminación del recurso de revisión e inclusión de precedentes vinculantes de las Comisiones.

\subsection{Delegación de facultades a entidades privadas}

Previamente a pronunciarnos acerca de las modificaciones más relevantes de los procedimientos seguidos ante Indecopi primeramente manifestaremos los alcances de la modificación al artículo 105 del Código de Consumo. Así tenemos que la parte pertinente del citado artículo señala lo siguiente:

“(...)el Indecopi, previo acuerdo de su Consejo Directivo, puede constituir órganos resolutivos de procesos sumarísimos de protección al consumidor (...) crear comisiones adicionales conforme lo justifique el aumento o disminución de la carga procesal o las necesidades de gestión requeridas para la mejor tramitación de los procedimientos a su cargo; o celebrar convenios con instituciones públicas o privadas, debidamente reconocidas para, de acuerdo a sus capacidades, delegarle facultades o las de secretaría técnica (...) Asimismo, el Consejo Directivo emite las disposiciones para la gestión más eficiente de los procedimientos a cargo del Indecopi".
La Exposición de Motivos del Decreto Legislativo $1308^{(36)}$ sostiene que la modificación del artículo 105 obedece a la delegación de facultades a instituciones privadas tales como asociaciones de consumidores, colegios profesionales o universidades, con la finalidad de "ampliar las posibilidades de acceso de los consumidores a información o a la justicia de consumo".

En el Sistema de Arbitraje de Consumo, de acuerdo al artículo 138 del Código de Consumo, las Juntas Arbitrales, que cuentan con la característica de un arbitraje institucional, cuya función es organizar el arbitraje de consumo ${ }^{(37)}$, se constituyen en los gobiernos regionales y locales. Cabe preguntarse si esta ampliación de delegación de facultades a particulares también se podría aplicar al Arbitraje de Consumo.

¿Es extraña la delegación de facultades de la administración a entidades privadas? Se cita como antecedente el Convenio de Delegación de Funciones No. 025-2002/CC ${ }^{(38)}$ suscrito entre INDECOPI y la Universidad de Lima de fecha 13 de diciembre de 2002, con duración de dos años y cuyo objeto fue garantizar el funcionamiento de una Oficina Descentralizada de INDECOPI - ODI a cargo de la entidad educativa, y con una contraprestación de S/ 20,600.00 mensuales. Este convenio fue

(35) Publicado en el Diario Oficial "El Peruano" el 30 de diciembre de 2016.

(36) Presidencia del Consejo de Ministros, "Exposición de Motivos del Decreto Legislativo que modifica el Código de Protección y Defensa del Consumidor, Ley 29571," http://spij.minjus.gob.pe/Graficos/Peru/2016/Diciembre/30/EXP-DL-1308.pdf (consultada el 29 de enero de 2017).

(37) De acuerdo al artículo 138 del Código de Consumo "la Autoridad Nacional de Protección del Consumidor (entiéndase Indecopi por el artículo 135 del Código de Consumo) constituye las juntas arbitrales en cada localidad, en coordinación con los gobiernos regionales y locales, a fin de que éstas organicen el sistema y lo promuevan entre los agentes del mercado y los consumidores". Según el artículo 5.1 del Decreto Supremo 046-2011-PCM - Reglamento del Arbitraje de Consumo, las Juntas Arbitrales "son los órganos constituidos al interior de entidades de la administración pública, cuya finalidad consiste en organizar el Sistema de Arbitraje de Consumo y promoverlo entre los agentes del mercado y los consumidores de su localidad. Asimismo, se encargan de brindar servicios administrativos y de secretaría técnica a los órganos arbitrales, lo que implica prestar el personal de apoyo, la infraestructura y el soporte financiero que resulten necesarios para su funcionamiento".

(38) Obtenido mediante Carta No. 337-2009/GEG-Sac de fecha 22 de octubre de 2009, la cual responde nuestra solicitud de acceso a la información del 14.10.09. 
Moisés Rejanovinschi Talledo

ampliado y renovado hasta el 31 de diciembre de $2002^{(39)}$. Las funciones delegadas, conforme la Cláusula Quinta del Convenio, comprendieron: recepción de reclamos de los consumidores para ser tramitados ante el Sistema de Apoyo al Consumidor, recepción de solicitudes de registro y denuncias de las Oficinas de Signos Distintivos, Derechos de Autor e Invenciones y Nuevas Tecnologías, Comisión de Protección al Consumidor y Represión de la Competencia Desleal, Libre Competencia y Acceso al Mercado, así como facultades para recibir y resolver Procedimientos Concursales.

Si bien no es posible determinar los motivos de resolución del convenio, una hipótesis que planteamos es la posible disminución en la carga procesal de procedimientos concursales. En cuanto a las funciones en el ámbito de la Protección al Consumidor se limitaron a una orientación y mesa de partes si comparamos con la delegación de facultades en procedimientos concursales, por el que la institución delegada tuvo potestad de resolver dichas controversias. Si se delegaron facultades de resolver controversias en el ámbito concursal, a una entidad privada, por qué no podría hacerse lo propio en el arbitraje de consumo. Deberían constituirse las Juntas Arbitrales en instituciones o entidades, sean públicas o privadas, como Universidades, Colegios Profesionales, o Municipalidades siempre que cumplan un perfil adecuado (Rejanovinschi 2011, 54-6).

Entonces, una conclusión preliminar consistiría en afirmar que el artículo 105 no se podría utilizar para ampliar las Juntas Arbitrales a entidades privadas por las siguientes consideraciones: (i) si inicialmente se analiza el contenido del artículo 105 se puede entender que la delegación de facultades a entidades privadas es para la tramitación de procedimientos administrativos que busquen conocer las presuntas infracciones al Código de Consumo, tales como los procedimientos sumarísimos y ordinarios; y, (ii) no se ha modificado el artículo 138 del Código de Consumo.

Sin embargo, dicha conclusión debe matizarse con la publicación de la Resolución de la Presidencia del Consejo Directivo del Indecopi No. 30-2017-INDECOPI/COD, el mismo que aprueba la publicación del proyecto de "Directiva que regula la delegación de facultades de difusión y educación en materia de protección al consumidor", en adelante Proyecto de Delegación de Facultades de Difusión y Educación. El sustento del mismo, según, su parte considerativa, es el segundo párrafo del artículo 105 del Código - el mismo que comentamos anteriormente -, la ejecución de la política nacional de protección al consumidor (artículo 136 del Código de Consumo), la promoción de cultura de protección al consumidor (el artículo VI.8 del Código de Consumo) y el Eje de Política 1 de Política de Protección al Consumidor.

El Eje 1 de la Política de Protección al Consumidor tiene como objetivo "fomentar que los agentes del mercado conozcan los derechos de los consumidores y dispongan de información relevante para mejores decisiones de consumo" y como lineamientos estratégicos tenemos la orientación al consumidor brindándole información, poner a disposición de los agentes de mercado información sobre protección al consumidor con énfasis en uso de tecnologías de la información, y capacitar a los agentes de mercado en materia de protección al consumidor. Sobre este último lineamiento estratégico consiste el Proyecto de Delegación de Facultades de Difusión y Educación.

De una simple lectura del ámbito de aplicación tenemos que, de aprobarse el proyecto, se aplicará para la delegación de facultades de difusión y educación, en temas de protección al consumidor, a las asociaciones de consumidores, colegios profesionales, universidades y otras instituciones públicas o privadas. En sentido estricto, el proyecto de Directiva no se sustenta el artículo 105 del Código (delegación de facultades a entidades privadas), sino en el artículo VI.8 sobre políticas públicas y en la Política de Protección al Consumidor.

Consideramos que debería extenderse la ampliación de facultades para que entidades

(39) Obtenido mediante Carta No. 337-2009/GEG-Sac de fecha 22 de octubre de 2009 


\author{
Protección al consumidor y propuesta Estatal en autorregulación privada y procedimientos \\ administrativos: una aproximación inicial \\ Consumer protection and State proposal in private self-regulation and administrative \\ procedures: an initial approach
}

privadas puedan funcionar como Juntas Arbitrales de Consumo pues existen razones de fuerza. El artículo VI. 6 del Código de Consumo - citado anteriormente en el presente documento - garantiza mecanismos eficaces y expeditivos para resolver controversias, promoviendo, entre otros, el arbitraje de consumo.

Al mismo tiempo, el Eje de Política 3 de la Política de Protección al Consumidor tiene como objetivo "promover el establecimiento de mecanismos expeditivos de prevención y solución de conflictos a nivel nacional, impulsando su simplificación". Entre los lineamientos estratégicos del Eje 3 se impulsará el desarrollo de juntas arbitrales. Si los gobiernos locales y regionales no han mostrado interés, debe ofrecerse a instituciones privadas, siempre que cumplan con un perfil adecuado.

Por otra parte, se ha creado la Junta Arbitral Piloto en la Sede Central de Indecopi ante la falta de intención de los gobiernos regionales y locales, adicionando la cuestionable denegación de otorgar indemnizaciones por la autoridad administrativa (Rejanovinschi 2015, 235-241). Si se delegan facultades para resolver infracciones en materia de protección al consumidor, por qué no delegar facultades para que se instalen Juntas Arbitrales en instituciones privadas.

\subsection{Formas autocompositivas de conclusión del procedimiento administrativo}

La modificación reciente de diversos artículos del Código de Consumo tiene como finalidad impulsar las formas autocompositivas de conclusión del procedimiento administrativo sancionador seguido ante Indecopi. En términos generales las formas autocompositivas permiten que las partes, en un proceso ordinario, renuncien o cedan total o parcialmente a sus pretensiones para que concluya la controversia. La autocomposición puede ser unilateral (como el desistimiento o allanamiento) o bilateral (como la conciliación o transacción) (Priori 2001, 37).

En el procedimiento sancionador seguido ante Indecopi con la finalidad resolver una controversia entre proveedores y consumidores, si bien se inicia de oficio a iniciativa de la autoridad, también es posible que se inicie por denuncia del consumidor afectado o potencialmente afectado, por una asociación de consumidores (si representan consumidores o asociados o alegan intereses colectivos o difusos), según el artículo 107 del Código de Consumo. Por otra parte la pretensión del denunciante será el otorgamiento de una medida correctiva reparadora.

A diferencia de un proceso seguido en la vía judicial, en el procedimiento administrativo la regla general será que el consumidor ocupe la calidad de denunciante, salvo el supuesto de denuncia maliciosa o un incumplimiento de acuerdo conciliatorio, conforme el artículo 106 del Código de Consumo.

Es por ello que la finalidad de impulsar las formas autocompositivas contribuyen a brindar de manera célere la resolución de controversias, incluso dentro del procedimiento administrativo sancionador.

Así tenemos que el Decreto Legislativo 1308 ha modificado el artículo 106 literal b) del Código, ampliando los procedimientos sancionadores no solo al incumplimiento de un acuerdo conciliatorio, sino a cualquier "otro acuerdo que de forma indubitable deje constancia de la manifestación de voluntad expresa de las partes de dar por culminada la controversia". Es decir, además de la conciliación puede incluirse la transacción. Esta modificación también se ha incluido en el artículo 108 del Código de Consumo, por la cual se considera como un supuesto de infracción administrativa el incumplimiento de "cualquier otro acuerdo que de forma indubitable deje constancia de la manifestación de voluntad expresa de las partes de dar por culminada la controversia".

De acuerdo al artículo 1302 del Código Civil, por la transacción "las partes haciéndose concesiones recíprocas, deciden sobre algún asunto dudoso o litigioso, evitando el pleito que podría promoverse o finalizando el que está iniciando" teniendo calidad de cosa juzgada. Las concesiones recíprocas implican mutua renuncia, sacrificando las partes su interés propio con la finalidad de concluir el conflicto. 
Moisés Rejanovinschi Talledo

Si solo una de las partes renuncia no estaremos frente a una transacción, además la reciprocidad no debe entenderse como igualdad de sacrificios en la cesión que realicen las partes (Priori 2001, 41).

En el desistimiento el consumidor renuncia al procedimiento iniciado en la vía administrativa, o a su pretensión o medida correctiva solicitada. La posición de la Sala de Protección al Consumidor consistía en no otorgar el desistimiento luego de culminada la primera instancia administrativa, pues "cuando la autoridad se ha pronunciado e impuesto una sanción, la sanción pertenece al Estado y no puede dejarse sin efecto por pedido de un particular"(40). Con la modificación introducida en el artículo 189.5 de la Ley 27444 - Ley del Procedimiento Administrativo General y la inclusión del artículo 107-A del Código de Consumo será factible el desistimiento antes que se agote la vía administrativa.

En lo referente a la Ley 27444 el artículo 189.5, modificado por el Decreto Legislativo 1272, señala que el desistimiento "se puede realizar en cualquier momento antes de que se notifique la resolución final que agote la vía administrativa". En la inclusión del artículo 107-A del Código de Consumo se regula como una forma de conclusión anticipada del procedimiento de oficio por denuncia de parte el desistimiento, del procedimiento o pretensión, "antes de la notificación de la resolución que agota la vía administrativa”.

Cabe añadir, reforzando que el último párrafo del artículo 106 del Código de Consumo, modificado por el Decreto Legislativo 1308 , señala que "la regulación propia del Derecho Procesal Civil es aplicable solo en cuanto sea compatible con el régimen administrativo". Existe una diferencia entre el desistimiento de la pretensión actualmente regulada en la vía administrativa en comparación con la vía civil: en la vía civil el desistimiento de la pretensión se efectúa antes de la sentencia de la primera instancia (en la vía administrativa se puede en la primera y segundan instancia), salvo que sea convencional ${ }^{(41)}$. Es por ello que el desistimiento es más permisivo en la vía administrativa.
El allanamiento y el reconocimiento también se ha reconocido expresamente en la modificación introducida por el Decreto Legislativo 1308 al artículo 112.3 del Código de Consumo, como culminación del procedimiento y también como atenuante, dependiendo de los derechos que están controvertidos:

"En los procedimientos de oficio promovidos por una denuncia de parte, cuando el proveedor se allana a la denuncia presentada o reconoce las pretensiones en ella contenidas, se da por concluido el procedimiento liminarmente, pudiendo imponerse una amonestación si el allanamiento o reconocimiento se realiza con la presentación de los descargos; caso contrario la sanción a imponer será pecuniaria. En aquellos casos en que el allanamiento o reconocimiento verse sobre controversias referidas a actos de discriminación, actos contrarios a la vida y a la salud y sustancias peligrosas, se considera como un atenuante pero la sanción a imponer será pecuniaria. En todos los supuestos de allanamiento y reconocimiento formulados con la presentación de los descargos, se exonera al denunciado del pago de los costos del procedimiento, pero no de las costas".

El Código de Consumo no define al allanamiento ni al reconocimiento, por lo que deberemos recurrir en esta ocasión al Código Procesal Civil. En el allanamiento, según el artículo 330 del Código Procesal Civil, el demandado se encuentra de acuerdo con la pretensión del demandante. Haciendo una analogía al ámbito administrativo, el proveedor

(40) Resolución No. 3448-2012-SPC-INDECOPI, numeral 21

(41) Según el artículo 342 del Código Procesal Civil. De acuerdo a Priori, y en opinión que compartimos, la última frase del artículo 342 "salvo que sea convencional" es un error pues el desistimiento es un acto unilateral y la frase "salvo que sea convencional debe entenderse como una conciliación o transacción. (PRIORI, 2001, p. 40). En el artículo 3232 del Código Procesal Civil la oportunidad de presentar una conciliación entre las partes se da antes de sentencia de segunda instancia, y la transacción se puede presentar incluso en casación, de acuerdo al artículo 334 del Código Procesal Civil. 


\author{
Protección al consumidor y propuesta Estatal en autorregulación privada y procedimientos \\ administrativos: una aproximación inicial \\ Consumer protection and State proposal in private self-regulation and administrative \\ procedures: an initial approach
}

denunciado estaría conforme con la medida correctiva solicitada por el consumidor denunciante, como por ejemplo la solicitud de reparar productos, el cambio de uno por otro de idéntica o similar características. Imaginemos el siguiente escenario: supongamos que un consumidor, por una denuncia por infracción al deber de idoneidad, solicita como medida correctiva reparadora el cambio de un producto por uno de similares características, pese a que la reparación es posible.

En principio contravendría el artículo 115.1.b) del Código por el cual se puede solicitar "cambiar productos por otros de idénticas o similares características, cuando la reparación no sea posible o no resulte razonable según las circunstancias", sin embargo, si el proveedor quiere concluir la controversia, y no se discute un acto sobre discriminación, acto que afecte la vida y salud o una sustancia peligrosa, bajo un análisis costo - beneficio podría decidir allanarse a la pretensión del consumidor denunciante.

En el reconocimiento, de acuerdo al Código Procesal Civil, el demandado se encuentra de acuerdo con la pretensión, los hechos y la fundamentación jurídica. A manera de ejemplo, si se denuncia a una entidad financiera porque un cajero automático no brindó al consumidor la totalidad del dinero en efectivo que solicitó, deberá reconocer los hechos (no entrará a revisar las cámaras de los cajeros u otros elementos que sirvan para sustentar una defensa) y la infracción al deber de idoneidad, con lo cual reconocería fallas en el servicio que brinda, pero bajo un análisis costo - beneficio sea más conveniente para el proveedor. Sin embargo, tendrá que evaluar en el reconocimiento que los hechos reconocidos pueden servir como herramientas para una futura denuncia de oficio por la autoridad administrativa.

Estas formas autocompositivas serán eficientes si su función es que culmine la controversia y si no se afectan intereses de terceros, pues se privilegia lo que acuerden las partes culminando la controversia, ahorrando esfuerzos en tiempo y dinero.

El acuerdo entre las partes también se privilegia con la modificación de la parte pertinente del primer párrafo del artículo 115.1 referida a las medidas correctivas reparadoras: "en caso el órgano resolutivo dicte una o varias medidas correctivas, debe considerar lo acordado por las partes durante la relación de consumo". Debe tenerse en cuenta que lo que acuerden las partes durante la relación de consumo no puede ser menor a lo establecido en la garantía legal, en concordancia con el artículo 20.a del Código de Consumo, y también que no nos encontremos ante un supuesto de cláusula abusiva, esto último indicado en el artículo 4.8 de la Resolución de Presidencia del Consejo Directivo del Indecopi No. 24-2017-INDECOPI/COD - Proyecto de Directiva que regula los procedimientos de protección al consumidor previstos en el Código de Protección y Defensa del Consumidor ${ }^{(42)}$.

\section{3. ¿Rechazo liminar de la denuncia?}

Un rechazo liminar de una demanda o acción legal se determina cuando no existe duda de su improcedencia y por tanto ni siquiera debe admitirse y posteriormente correrse traslado a la otra parte, cuando la demanda está "condenada al fracaso", pero si existen elementos que permiten un debate el juzgador no debe utilizar esta herramienta procesal(43). En el ámbito del procedimiento administrativo el rechazo liminar implicaría de plano declarar la improcedencia de la misma, sin admitirla ni correr traslado de la misma al denunciado.

Se ha modificado la parte final del artículo 108 del Código de Consumo que establece la conclusión del procedimiento por improcedencia, en las denuncias de parte, por los siguientes supuestos:

a) Si el denunciante no ostenta la calidad de consumidor final, conforme a la definición del Código de Consumo. En este supuesto nos encontraremos ante una falta de legitimidad para obrar activa, si estamos por

(42) Publicado en el Diario Oficial "El Peruano" el 16 de febrero de 2017.

(43) Sentencia del Tribunal Constitucional recaída en el Expediente No. 3418-2013-PA-TC, Fundamento Jurídico No. 3. 


\section{Moisés Rejanovinschi Talledo}

ejemplo ante un microempresario que realiza una denuncia de un producto que forma parte de su giro del negocio.

b) Si el denunciado no califica como proveedor según el Código de Consumo. En este supuesto nos encontraremos ante una falta de legitimidad para obrar pasiva, a manera de ejemplo si el proveedor no actúa como tal de manera habitual.

c) Si no existe una relación de consumo. Si bien el Código señala que una relación de consumo es la "relación por la cual un consumidor adquiere un producto o contrata un servicio a cambio de una contraprestación económica"(44), debe entenderse que la contraprestación puede ser en dinero o en especie. A manera de ejemplo, en las redes sociales una persona puede crear un perfil de usuario de manera gratuita, pero puede autorizar al manejo de sus datos al proveedor.

d) Si ha prescrito la facultad de la autoridad administrativa para determinar la existencia de infracción administrativa.

e) Si existe falta de legitimidad o interés para obrar.

f) Si el proveedor subsana o corrige la conducta constitutiva de infracción administrativa con anterioridad a la notificación de la imputación de cargos. Esto último puede configurarse como falta de interés para obrar.

Como puede observarse, en más de uno de los siguientes supuestos será necesario que la autoridad, antes de resolver, contraste la información que puede ofrecer el proveedor en su contestación, y finalmente se genera convicción para determinar si se concluye el procedimiento por alguna causal de improcedencia. De lo expuesto, no debe aplicarse el rechazo liminar de una denuncia administrativa, considerando además la aplicación del principio pro actione o favorecimiento del proceso del consumidor supuestamente afectado.
Indicamos anteriormente que existen dos clases de procedimientos sancionadores, diferenciados por materias y cuantías, siendo ordinarios y sumarísimos ${ }^{(45)}$. En la Directiva del Procedimiento Sumarísimo se encuentra esta potestad de rechazo liminar: cuando el denunciante no sea consumidor, o el denunciado no califique como proveedor, no exista relación de consumo o hubiese acuerdo entre las partes ${ }^{(46)}$. Varios de los supuestos ameritan un análisis razonable que, para determinar la improcedencia de la denuncia, no debe aplicarse al inicio del procedimiento.

Al parecer, ni el Proyecto de Directiva que regula los procedimientos en materia de protección al Consumidor, ni el Proyecto de Regulación del Procedimiento Sumarísimo ${ }^{(47)}$ han recogido la propuesta del rechazo in limine, tal como se encuentra en la Directiva del Procedimiento Sumarísimo.

\subsection{Eliminación del recurso de revisión e inclusión de precedentes vinculantes de las Comisiones}

Como indicamos anteriormente, existen los procedimientos sancionadores sumarísimo y ordinario, seguidos ante Indecopi. Una crítica al modelo del procedimiento sumarísimo es la modificación, efectuado por el Decreto Legislativo 1308, de una parte pertinente de su artículo 125, por la cual es competente para resolver denuncias por "falta de entrega del producto, con independencia de su cuantía". Anteriormente también era competencia de los procedimientos sumarísimos la demora en la entrega del producto.

(44) Conforme al artículo IV.5 del Código de Consumo.

(45) Según los artículos 124 y siguientes del Código de Consumo.

(46) Según el artículo 4.3.8 de Directiva del Procedimiento Sumarísimo, Directiva 04-2010/DIR-COD-INDECOPI y Directiva 032014/DIR-COD-INDECOPI.

(47) Resolución de la Presidencia del Consejo Directivo del Indecopi No. 24-2017-INDECOPI/COD y Resolución de la Presidencia del Consejo Directivo del Indecopi No. 25-2017-INDECOPI/COD, ambas publicadas en el Diario Oficial "EI Peruano" el 16 de febrero de 2017. 


\section{Protección al consumidor y propuesta Estatal en autorregulación privada y procedimientos administrativos: una aproximación inicial Consumer protection and State proposal in private self-regulation and administrative procedures: an initial approach}

La demora en la entrega de un producto también puede afectar al consumidor, pudiendo generarse daños adicionales. Por ejemplo, si una persona contrata la adquisición de un vehículo o un inmueble y no le entregan el bien en la fecha pactada, tendrá que incurrir en costos no previstos, como el alquiler del vehículo o inmueble hasta que el proveedor cumpla lo pactado. ¿Será entonces la Comisión de Protección al Consumidor competente, la que en primera instancia administrativa resolverá la controversia en un procedimiento ordinario? Es un extremo que se debe tener en cuenta para futuras modificaciones del Código, pues la finalidad es que el consumidor sea protegido de manera efectiva.

A su vez, el artículo 125 del Código señala que no se puede conocer vía sumarísimo las siguientes materias: productos o sustancias peligrosas, actos de discriminación o trato diferenciado, servicios médicos, actos que afecten intereses colectivos o difusos. Entiéndase que las materias no comprendidas en el procedimiento sumarísimo se resuelven en el procedimiento ordinario.

Se parte del supuesto que el procedimiento sumarísimo, por resolverse en treinta días hábiles por instancia, debe ser más célere. Lo que se puede cuestionar es que la norma asuma que las materias reservadas para los procedimientos ordinarios sean siempre más complejas y no puedan atenderse siempre en el plazo de los treinta días hábiles. Una muestra de ello es una denuncia que puede interponer una asociación de consumidores contra un proveedor de un producto alegando que, si es un producto importado, no ha colocado los riesgos y advertencias en idioma castellano. ¿Merece el caso propuesto tal complejidad que no sea resuelto mediante sumarísimo? Adicionalmente, una denuncia por actos de discriminación ¿amerita siempre que se resuelva en el plazo de más de treinta días hábiles? No nos queda claro que determinadas materias se consideren complejas per se.

En el procedimiento sumarísimo, el esquema con anterioridad a la modificación introducida por el Decreto Legislativo 1308, era de dos instancias y un recurso de revisión: en primera instancia resolvía el Jefe del Órgano Resolutivo del Procedimiento sumarísimo, en vía de apelación resolvía la controversia la Comisión de Protección al Consumidor competente, y de manera extraordinaria se podía interponer un recurso de revisión, que resolvía la Sala de Protección al Consumidor. La finalidad del recurso de revisión consistía en examinar si se había dejado de aplicar, o se había aplicado erróneamente las normas del Código de Consumo o no se habían respetado los precedentes de observancia obligatoria. Con anterioridad a la modificación del Decreto Legislativo 1308 solo podía emitir precedentes de observancia obligatoria la Sala de Protección al Consumidor.

Ahora con la modificación del artículo 125 por el Decreto Legislativo 1308 se cuentan con solo dos instancias y la eliminación del recurso de revisión, siendo la primera instancia Jefe del Órgano Resolutivo del Procedimiento sumarísimo y en apelación resuelve la Comisión de Protección al Consumidor competente agotando la vía administrativa, la que puede ser cuestionada mediante el proceso contencioso - administrativo.

El sustento de la eliminación del recurso de revisión, según la Exposición de Motivos del Decreto Legislativo $1308^{(48)}$, radica que en muy pocos casos las instancias inferiores aplican incorrectamente el Código de Consumo, ya que "durante el periodo enero - octubre 2016 el $71.34 \%$ de los recursos de revisión fue declarado improcedente (...) y si se agregan los casos infundados, el porcentaje aumenta al 85.98\%". Además se afirma en la Exposición de Motivos que los consumidores que no se encuentren conformes con la decisión de la Comisión de Protección al Consumidor en vía de apelación pueden acudir al Poder Judicial.

Vemos dos objeciones a la motivación de la eliminación del recurso de revisión: primero,

(48) Presidencia del Consejo de Ministros, "Exposición de Motivos del Decreto Legislativo que modifica el Código de Protección y Defensa del Consumidor, Ley 29571," http://spij.minjus.gob.pe/Graficos/Peru/2016/Diciembre/30/EXP-DL-1308.pdf (consultado el 29 de enero de 2017). 
Moisés Rejanovinschi Talledo

acudir al contencioso - administrativo también se podía efectuar cuando resolvía el recurso de revisión la Sala de Protección al Consumidor; segundo, eliminar un recurso por estadística puede ser peligroso pues se deniega la tutela a ese porcentaje que en el que se analiza que se aplicó incorrectamente la norma, y se niega la capacidad de la administración corrija sus errores en sus fueros, como era mediante el recurso de revisión.

Además de eliminar el recurso de revisión se ha facultado a las Comisiones de Protección al Consumidor que emitan precedentes de observancia obligatoria, con la modificación del del artículo 14.1 a) y d) del Decreto Legislativo 1033 - Ley de Organización y Funciones de Indecopi

"artículo 14.1. Las Salas del Tribunal tienen las siguientes funciones:

a) Conocer y resolver en segunda instancia administrativa interpuestas contra los actos que ponen fin a la instancia (...) emitidos por Comisiones (...) salvo que las mismas no resulten apelables de acuerdo a la ley de la materia"

(...) d) Expedir precedentes de observancia obligatoria que interpreten de modo expreso y con carácter general el sentido de la legislación bajo su competencia, así como conocer en consulta los precedentes de observancia obligatoria emitidos por las Comisiones"

Para completar el panorama se ha modificado el artículo 21 literal j) del Decreto Legislativo 1033, facultando la emisión de precedentes de observancia obligatoria por las Comisiones de Protección al Consumidor:

"Expedir precedentes de observancia obligatoria que interpreten de modo expreso y con carácter general el sentido de la legislación bajo su competencia. En caso las Comisiones de Protección al Consumidor emitan una decisión que establezca un precedente de observancia obligatoria y la resolución final que lo contenga sea apelada, la Sala Especializada se pronunciará sobre el mismo al emitir su decisión final. De no interponerse recurso de apelación, las Comisiones de Protección al Consumidor remitirán de oficio el expediente concluido a la Sala Especializada para que se pronuncie al respecto"

Un precedente de observancia obligatoria, según el artículo VI de la Ley 27444 - Ley del Procedimiento Administrativo General, es aquel acto administrativo que al resolver un caso particular interprete de modo expreso y general el sentido de la legislación. Su finalidad será orientar a la ciudadanía acerca del alcance de la aplicación de una norma.

Si el concepto del precedente implica efectuar una interpretación general, y que vincule a los operadores jurídicos, cómo se extiende la facultad a las Comisiones de Protección al Consumidor cuando existe un superior jerárquico como la Sala de Protección al Consumidor. Si en el procedimiento sumarísimo la última instancia es la Comisión de Protección al Consumidor, cómo este precedente vincula a la Sala de Protección al Consumidor. A su vez, si existen comisiones de protección al consumidor a nivel nacional, divididas territorialmente y en algunos casos también por materias ${ }^{(49)}$, cómo pueden vincular a sus pares.

El artículo VI del Proyecto de Directiva que regula los procedimientos de protección al Consumidor indica que si la Comisión de Protección al Consumidor emite un precedente y no se interpone recurso de apelación en un procedimiento ordinario, o emite precedente como segunda instancia en un procedimiento sumarísimo y teniendo en cuenta que en este supuesto es última instancia administrativa, en ambos casos se eleva de oficio a la Sala de Protección al Consumidor para que se pronuncie y hasta ello la condición de precedente queda suspendida.

(49) Como las Comisiones de Protección al Consumidor de la ciudad de Lima. 
Protección al consumidor y propuesta Estatal en autorregulación privada y procedimientos administrativos: una aproximación inicial Consumer protection and State proposal in private self-regulation and administrative procedures: an initial approach

Si la condición de precedente es la facultad de efectuar una interpretación general ¿por qué necesita ser consultada ante el superior? Una alternativa sería que el máximo órgano administrativo sea el que cuente con la exclusiva facultad de emitir precedentes. A su vez, en el proyecto de directiva se afirma que la Sala solo revisa la condición de precedente, con lo que se entiende que el resto del acto administrativo tendrá plenos efectos. Qué pasaría si la Sala de Protección al Consumidor revisa el precedente y determina que no es válido, pues de acuerdo a la estadística citada en la Exposición de Motivos del Decreto Legislativo 1308, el cien por ciento de resoluciones que emite la Sala de Protección al Consumidor no son confirmadas.

Existen las siguientes preguntas abiertas: cuáles serán los criterios para la revisión, cuál será el plazo que tiene la Sala de Protección al Consumidor. En cuanto a la primera consulta, se examinará si la interpretación de alcance general es correcta o no, según lo que entienda la Sala. Si bien se suspende la condición de precedente, de acuerdo al proyecto, es posible que si la Sala determine que no se ha emitido de manera correcta el precedente, o esta interpretación de alcance general, repercuta en lo que ha resuelto la Comisión. En cuanto al plazo que tiene la Sala para pronunciarse, serán treinta días hábiles por instancia como el sumarísimo, ó ciento veinte días hábiles como el procedimiento ordinario. La celeridad que se pretende lograr en el caso del sumarísimo puede ser cuestionada.

Una posibilidad para volver a la celeridad sería plantear el regreso a los procedimientos ordinarios en los que solo existe la Comisión de Protección al Consumidor como primera instancia administrativa y la Sala de Protección al Consumidor como segunda. Sea el esquema que se proponga, en ocasiones la solución estará más allá de una reforma legislativa, pues será necesario una inversión logística suficiente, y con mayor cantidad de personal, para que la expectativa creada por el Estado a favor de los consumidores, de resolver sus controversias en treinta días hábiles, sea satisfecha.

\section{Uso de redes sociales para interponer reclamos}

Las redes sociales están siendo consideras como una alternativa por los consumidores para obtener justicia. Como consecuencia de la conexión a internet ahora los consumidores, en vez de utilizar mecanismos legales como el libro de reclamaciones o interponer una acción legal, etiquetan a los proveedores en redes sociales, como Facebook o Twitter, cuando existe alguna disconformidad con el producto o servicio. Esta publicación puede ser compartida por los contactos del consumidor, amigos de amigos, hasta trascender el ámbito privado y viajar a la prensa tradicional, que también se encuentra interconectada, convirtiéndose en la práctica el reclamo en viral.

Un consumidor con un teléfono celular o móvil puede en el instante capturar la discrepancia de lo ofrecido por el proveedor y subirlo a internet: puede ser testigo de un acto de discriminación, o la falta de higiene de un establecimiento de fastfood, o incluso

Como está expuesto el prestigio del proveedor de manera viral, y es necesario el manejo adecuado de un community manager, un reclamo en redes puede ser perjudicial si no es atendido a tiempo y de manera adecuada. Recordemos que las marcas tienen una función indicadora de la calidad, función que brinda información a los consumidores, y también transmite prestigio.

Posiblemente los consumidores acudan a las redes sociales como medio de reclamo pues los mecanismos que brinda el Estado (como los procedimientos seguidos ante Indecopi) o los particulares (como la autorregulación) no sean suficiente para ellos. El consumidor desea que su reclamo sea resuelto de la manera más rápida posible.

En el entorno digital, de acuerdo a las recomendaciones de la OECD, los proveedores no deben negar la posibilidad de los consumidores de emitir calificaciones negativas (OECD 2016, 11). Sin embargo, ambas partes involucradas, sean consumidores y proveedores, deben emitir información que 
Moisés Rejanovinschi Talledo

sea veraz, pues existen ocasiones en que denuncias emitidas en internet son desmentidas. A su vez, que determinados consumidores califiquen positivamente en internet o aplicaciones un producto o servicio no implica que el proveedor se encuentre exonerado de brindar información relevante. No se puede saber si, por ejemplo, existen "consumidores" que puedan tener una vinculación( ${ }^{(50)}$ con un proveedor e indicar reseñas positivas en redes sociales, sin que terceros conozcan si efectivamente ese consumidor está realmente conforme con el producto o servicio y si ha tenido una experiencia de consumo verdadera.

Como contraparte, también puede existir el abuso de derecho en el caso de las afirmaciones maliciosas que se puedan hacer en redes sociales. La pregunta sería si un proveedor sería amparado en el ámbito de la protección al consumidor, ya que existe la posibilidad de iniciar un procedimiento por denuncia maliciosa.

La aplicación del artículo 106 literal e) del Código estaría pensaba únicamente para denuncias administrativas interpuestas ante Indecopi de mala fe, siendo también sancionable la interposición de denuncias de mala fe por las asociaciones de consumidores, pudiendo ser suspendidas o cancelado su registro, de acuerdo al artículo 154 del Código de Consumo. En tal sentido, el proveedor debería acudir a otra vía legal para los reclamos de mala fe que se materialicen en redes sociales. No se puede convertir el mundo virtual en una ley de la selva, ya que ambas partes en una relación de consumo tienen derechos que deben ejercer de manera responsable, y a su vez obligaciones.

Debe tenerse presente, además, que las partes concurren a un mercado de buena fe, y este debe ser el comportamiento imperante en las relaciones de consumo. Para ello el Código de Consumo ha reconocido en su artículo V.5 el Principio de Buena Fe:

"En la actuación en el mercado y en el ámbito de vigencia del presente Código, los consumidores, los proveedores, las asociaciones de consumidores, y sus representantes, deben guiar su conducta acorde con el principio de la buena fe de confianza y lealtad entre las partes (...)".
Se exige buena fe, tanto para las transacciones presenciales y virtuales. Las partes no deben olvidarse de esta exigencia, debiendo ser veraces en las afirmaciones que realicen en cualquier contexto.

Lo que se ha pretendido resaltar en el presente documento son las opciones que tiene el consumidor para resolver sus controversias, desde la autorregulación, pasando por las modificaciones efectuadas a los procedimientos seguidos ante Indecopi, para culminar con la efectividad que pueden tener las redes sociales en comparación con los mecanismos generados por el Estado y los privados.

\section{Bibliografía}

Cayon De Las Cuevas, Joaquín. 2011. "Regulación y autorregulación en el comercio electrónico: especial consideración de los códigos de conducta como instrumento de soft law”. En Coord. Julio Álvarez Rubio. Director Jorge Tomillo Urbina. La protección jurídica de los consumidores como motor de desarrollo económico. Navarra: Civitas.

Comisión de las Comunidades Europeas. 1993. Libro Verde Acceso de los consumidores a la justicia y solución de litigios en el mercado único, COM (93) 576 Final. Bruselas.

Darnaculleta Gardela, María Mercé. 2002. Derecho administrativo y autorregulación: la autorregulación regulada. Tesis para optar el grado de Doctora en Derecho. http://dugidoc.udg.edu/bitstream/handle/10256/4787/ tmdg.pdf?sequence=10 (consultada el 22 de febrero de 2017).

Fernández-Novoa, Carlos. 1978. "Las funciones de la marca". En Actas de Derecho Industrial, Universidad Santiago de Compostela, No. 05

(50) A manera de ejemplo, una relación de parentesco con representantes o accionistas del proveedor. 


\section{Protección al consumidor y propuesta Estatal en autorregulación privada y procedimientos administrativos: una aproximación inicial Consumer protection and State proposal in private self-regulation and administrative procedures: an initial approach}

INDECOPI - Instituto Nacional de Defensa de la Competencia y de la Protección de la Propiedad Intelectual - Indecopi. 2016. Resolución de la Presidencia del Consejo Directivo del Indecopi No. 216-2016-INDECOPI/COD que aprueba las "Recomendaciones generales para la creación de Defensorías del Consumidor".

Véase Instituto Nacional de Defensa de la Competencia y Propiedad Intelectual. 2016. "Anuario de Estadísticas Institucionales 2015." https://www.indecopi.gob.pe/ documents/20182/387120/Anuario+actualizado/ cd5afe59-7127-4425-957a-4e77687e9a88 (consultada el 07 de abril de 2017)

Monroy, Juan. Las excepciones en el Código Procesal Civil. Themis- Revista de Derecho 28 (1994): 119-29

ONU - Organización de las Naciones Unidas. 2016. Directrices para la Protección del Consumidor. Nueva York y Ginebra

OECD - ORGANISATION FOR ECONOMIC CO-OPERATION AND DEVELOPMENT. 2015. Industry self-regulation: role and use in supporting consumer interests. Committee on Consumer Policy. DSTI/CP(2014)4/FINAL

2016. Consumer Protection in e-commerce. OECD Recommendation.
Osterling Parodi, Felipe, 1985. La indemnización por daños y perjuicios, En: Libro homenaje a José León Barandiarán Lima : Cultural Cuzco.

Priori, Giovanni. 2001. Formas autocompositivas de conclusión del proceso en el Código Procesal Civil. Proceso \& Justicia. Revista de Derecho Procesal 1.

Rejanovinschi Talledo, Moisés. 2011. ¿Defendiéndonos de manera adecuada? El rol de las asociaciones de consumidores en el Perú. Tesis de Maestría en Derecho de la Propiedad Intelectual y de la Competencia. Lima: PUCP.

Rejanovinschi Talledo, Moisés. 2015. Los dilemas para consumir justicia: algunos alcances de la tutela procesal del consumidor en la vía administrativa y el arbitraje de consumo. Revista Derecho PUCP 75: 231-51.

Rocco, Ugo. 1982. Tratado de Derecho Procesal Civil. Tom. I. Buenos Aires. Temis: Bogotá- Depalma.

Soria Aguilar, Alfredo y Osterling Letts, Madeleine. 2014. Contratos modernos. Elementos esenciales y reglas aplicables para acuerdos comerciales. Lima. Universidad Peruana de Ciencias Aplicadas.

Weingarten, Celia. 2011. La confianza como elemento superador de la asimetría para consumidores y usuarios. En Manual de los Derechos de Usuarios y Consumidores. Directores Carlos Ghersi y Cecilia Weingarte. Buenos Aires: La Ley. 